\title{
DISCOLORATION OF WATER CONTAMINATED BY THE TEXTILE DYE RED TS3B UTILIZING ULTRAVIOLET RADIATION AND ZnO AS A PHOTOCATALYST
}

\author{
DERLY ORTIZ-ROMEROI , STAMBER RAMÍREZ-REVILLA ${ }^{2 *}$ \\ ${ }^{1}$ Laboratorio del Proyecto Mercurio, Facultad de Ciencias Farmaceúticas, Bioquímicas y Biotecnológicas, \\ Universidad Católica de Santa María (UCSM), Urb. San José s/n Umacollo, Arequipa-Perú. \\ ${ }^{2 *}$ Universidad Tecnológica del Perú (UTP), Av. Tacna y Arica 160, Arequipa-Perú.
}

\begin{abstract}
The current research project consisted of discoloring water contaminated by the textile dye Red TS3B, utilizing ultraviolet radiation and ZnO as a photocatalyst, towards this end, a spectrophotometric method for the quantification of dye was validated, and this method presented an adequate linearity and sensibility. For the discoloration trial run, a factorial design $\left(2^{2}\right)$, in order to optimize the experimental factors of $\mathrm{pH}$ and $\mathrm{ZnO}$ dosage per $250 \mathrm{~mL}$ of solution, was executed. The best discoloration was achieved at 180 minutes of photocatalytic reaction, when it worked with a $\mathrm{pH}$ of 11 and a dosage of $0.2 \mathrm{~g}$ of $\mathrm{ZnO}$ per $250 \mathrm{~mL}$ of colored solution, achieving a degradation percentage of $97.5 \%$ of dye in solution.
\end{abstract}

Keywords: Discoloration, contaminated water, Red TS3B, ultraviolet radiation, $\mathrm{ZnO}$.

\section{INTRODUCTION}

The textile industry is considered one of the biggest consumers of hydraulic resources in the world, generating a great quantity of effluents which end up being harmful to the environment [1].

Dyes are present in these textile effluents, and they often flow directly into different bodies of water, resulting in a dangerous situation because these can interfere with processes of photosynthesis normally carried out by the organisms living in these lakes and rivers [2]. Based on all of these precedents and in accordance with our local and national reality, Processes of Advanced Oxidation (PAO) become an extremely interesting alternative, and among them, photocatalysis with $\mathrm{ZnO}$ is appropriate in order to achieve effluent discoloration processes [3].

$\mathrm{ZnO}$ is considered a photocatalyst of the highest efficiency due to the fact that it possesses a wide gap of $3.2 \mathrm{eV}$ and a linking energy of great excitation $(60 \mathrm{meV})$. Due to these characteristics, it continues being widely researched for the removal of water and air pollutants and also for microbial disinfection [4]. The general reaction mechanism of $\mathrm{ZnO}$ is presented in Fig. 1 [5].

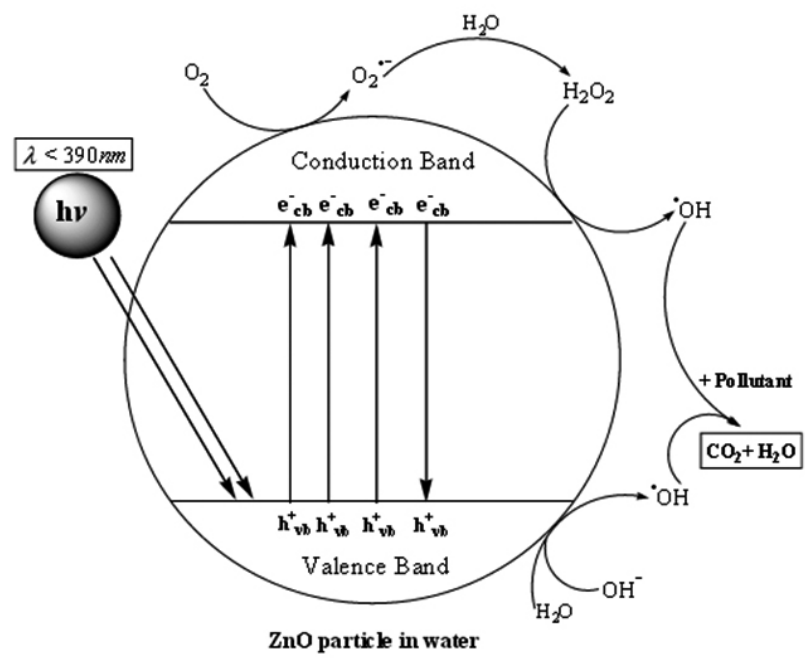

Figure 1. Photolytic reaction mechanism of $\mathrm{ZnO}$ in watery conditions.

\section{EXPERIMENTAL PROCEDURES}

In order to execute the present research project, distilled water $\left(1.0 \mu \mathrm{S} \mathrm{cm}^{-1}\right.$ a $\left.20^{\circ} \mathrm{C}\right)$, zinc oxide $(\mathrm{ZnO})$ from Central Drug House, sodium hydroxide, and sulfuric acid, all of which were of experimental and analytical quality, were utilized. The textile dye Red TS3B was provided by Engineer Fredy Molina from the company Franky \& Ricky in the city of Arequipa.
An ultraviolet light lamp (50 $\mathrm{Hz}$ and $30 \mathrm{~W}$ ) was utilized as a radiation source. In order to conduct the discoloration trial runs, a magnetic agitator CIMAREC was used along with $250 \mathrm{~mL}$ Petri dishes.

For the spectrophotometric analysis, a spectrophotometer Cary 60 UV-V from Agilent Technologies was utilized. In the same manner, for the $\mathrm{pH}$ measurement, a $\mathrm{pH}$-meter from Metrohm was employed, and for the measurement of volumes, type A volumetric burettes and pipettes of adequate range were utilized.

The statistical analysis of the data obtained was conducted with the programs Microsoft Excel 2013, Statagraphics Centurion XVI.II, and Origin Pro 9.0.

2.1 Granulometric adaptation of $\mathrm{ZnO}$

In order to achieve a uniform particle size, a sufficient quantity of $\mathrm{ZnO}$ went through a rigorous sifting process (size $\mathrm{N}^{\circ} 200$ ), drying it at $120^{\circ} \mathrm{C}$ for 4 hours and keeping it continuously in a desiccator.

2.2 Elaboration of a calibration graphic for the determination of the dye Red TS3B

A stock solution of $100 \mathrm{mg} \mathrm{L}^{-1}$ of the dye Red TS3B was prepared in order to obtain standard solutions of 5, 10,20,30,40,50 and $60 \mathrm{mg} \mathrm{L}^{-1}$. Subsequently, a spectral scan between 800 and $200 \mathrm{~nm}$ was conducted in order to determine the wavelength of maximum absorption, using the standard solution of $30 \mathrm{mg}$ $\mathrm{L}^{-1}$. Finally, the reading of the standard solutions was conducted and repeated three times in the spectrophotometer, utilizing distilled water as a target model.

2.3 Evaluation of the method's linearity

Assuming there is a linear relationship, which is directly proportional among absorbance and concentration, a linear regression was calculated for the method of minimal squares, obtaining it as an algebraic form:

$$
\begin{gathered}
y=a+b x \\
b=\frac{\sum x_{i} y_{i}-\frac{\sum x_{i} \sum y_{i}}{n}}{\sum x_{i}^{2}-\frac{\left(\sum x_{i}\right)^{2}}{n}} \\
a=\frac{\sum y_{i}-b \sum x_{i}}{n}
\end{gathered}
$$

Where $y$ is absorbance, $x$ is concentration, $a$ is the intercept and $b$ is the slope.

On the other hand, from the independent form to the appearance that the straight line takes, it is convenient to evaluate the correlation coefficient because in analytical practice, $r$ must be greater than 0.99 .

$$
r=\frac{\sum x_{i} y_{i}-\frac{\sum x_{i} \sum y_{i}}{n}}{\sqrt{\left(\sum x_{i}^{2}-\frac{\left(\sum x_{i}\right)^{2}}{n}\right)\left(\sum y_{i}^{2}-\frac{\left(y_{i}\right)^{2}}{n}\right)}}
$$


However, an indicator which ends up being more trustworthy for the linear correlation evaluation is a statistic test which permits one to find the value $t$.

$$
t=\frac{|r| \sqrt{n-2}}{\sqrt{1-r^{2}}}
$$

2.4 Determination of the detection limit and of method quantification

The detection limit was determined in order to become acquainted with the minimum quantity of analyte, which is possible to detect but not necessarily to quantify utilizing the proposed methodology.

$$
\mathrm{LOD}=\frac{y_{B}+3 S_{y / x}}{b} \cdot \frac{1}{\sqrt{n}}
$$

On the other hand, the quantification limit was determined in order to become acquainted with the minimum concentration of analyte which can be determined by the method in an exact manner.

$$
\mathrm{LOQ}=\frac{y_{B}+10 S_{y / x}}{b} \cdot \frac{1}{\sqrt{n}}
$$

2.5 Factorial design for the discoloration experiments

In order to research the effects of the variables which intervene in a process of photolytic discoloration, a two-level $\left(2^{2}\right)$ factorial design was conducted with only one trial run at each point. The variables under study were dosage of $\mathrm{ZnO}$ and $\mathrm{pH}$. Table 1 presents the fixed values for each variable.

Table 1. Variables and levels considered for the study.

\begin{tabular}{|c|c|c|}
\hline Variable & Low level $(-1)$ & High level $(+1)$ \\
\hline $\mathrm{ZnO}(\mathrm{g} / 250 \mathrm{~mL})$ & 0.05 & 0.20 \\
\hline $\mathrm{pH}$ & 3 & 11 \\
\hline
\end{tabular}

In order to conduct the discoloration studies, four solutions of the dye Red TS3B were prepared at a concentration of $50 \mathrm{mg} \mathrm{L}^{-1}$, adjusting the $\mathrm{pH}$ with solutions of $\mathrm{NaOH}$ and $\mathrm{H}_{2} \mathrm{SO}_{4}$ concentrated in agreement with the requirements presented in Table 2. The solutions were subsequently exposed to intense ultraviolet radiation (UV lamp), with $10 \mathrm{~mL}$ samples being taken every 30 minutes for three hours.

Table 2. Discoloration experiments for Red TS3B.

\begin{tabular}{|c|c|c|}
\hline Solution & $\mathrm{pH}$ & $\mathrm{ZnO}(\mathrm{g} / 250 \mathrm{~mL})$ \\
\hline 1 & 3 & 0.05 \\
\hline 2 & 11 & 0.20 \\
\hline 3 & 3 & 0.05 \\
\hline 4 & 11 & 0.20 \\
\hline
\end{tabular}

After having conducted the spectrophotometric determination of the samples obtained by way of the discoloration experiment, the percentage of degradation was calculated using the equation (8):

$$
\text { Degradation }(\%)=\frac{C_{0}-C_{f}}{C_{0}} \times 100
$$

Where $C_{0}$ is the initial concentration of dye and $C_{f}$ is the final concentration of dye subsequent to the photolytic process.

\section{RESULTS}

3.1 Calibration graphic for the determination of the dye Red TS3B

For the evaluation of method linearity, a graphic which related absorbency to concentration was elaborated. The experimental data for absorbency for each standard deviation are presented in Table 3, being read at $541 \mathrm{~nm}$.
Table 3. Absorbance data in order to evaluate method linearity.

\begin{tabular}{|c|c|c|c|c|c|}
\hline $\begin{array}{c}\text { Concentration } \\
\left(\mathrm{mg} \mathrm{L}^{-1}\right)\end{array}$ & Abs 1 & Abs 2 & Abs 3 & $\begin{array}{c}\text { Average } \\
\text { Abs }\end{array}$ & SD \\
\hline 5 & 0.0895 & 0.0892 & 0.0881 & 0.0889 & 0.0007 \\
\hline 10 & 0.1727 & 0.1736 & 0.1743 & 0.1735 & 0.0008 \\
\hline 20 & 0.3608 & 0.3613 & 0.3618 & 0.3613 & 0.0005 \\
\hline 30 & 0.5495 & 0.5484 & 0.5476 & 0.5485 & 0.0010 \\
\hline 40 & 0.7088 & 0.7322 & 0.7287 & 0.7232 & 0.0126 \\
\hline 50 & 0.9268 & 0.9239 & 0.9275 & 0.9261 & 0.0019 \\
\hline 60 & 1.1174 & 1.1158 & 1.1160 & 1.1164 & 0.0009 \\
\hline
\end{tabular}

Fig. 2 illustrates the linear regression obtained for the data presented in Table 3, a correlation coefficient $\left(r^{2}\right)$ of 0.9997 , a slope $(b)$ equal to 0.0187 and an intercept $(a)$ of -0.0115 were obtained, thus yielding the following equation:

$$
\text { Absorbance }=-0.0115+0.0187 \cdot \text { Concentration 9) }
$$

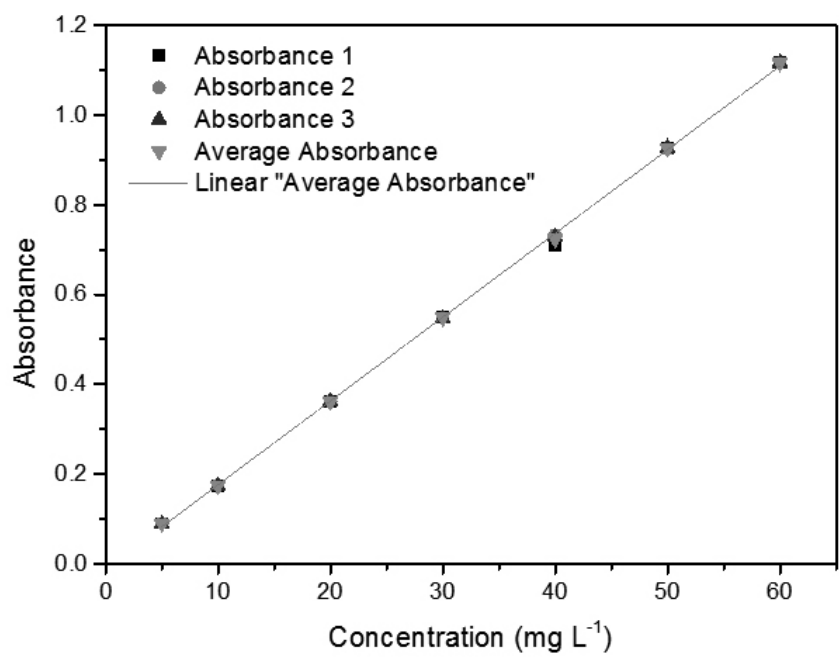

Figure 2. Calibration graphic for the determination of the dye Red TS3B.

Likewise, for the statistical analysis $t$, values of 129.07 and 2.57 for $t$ and $t$ respectively were obtained, with an elevated correlation among absorbance and concentration being observed.

3.2 Detection limit and method quantification

Table 4 presents the required results for the determination of the detection and quantification limits.

Table 4. Values for determining method sensitivity.

\begin{tabular}{|c|c|c|}
\hline \multicolumn{3}{|c|}{ Determination of LOD y LOQ } \\
\hline Result when $x$ is zero & $Y_{\text {blank }}$ & 0.0115 \\
\hline $\begin{array}{c}\text { Standard deviation of the } \\
\text { result when } x \text { is zero }\end{array}$ & $S_{\text {blank }}$ & 0.0009 \\
\hline Number of data & $N$ & 7 \\
\hline Slope & $B$ & 0.0187 \\
\hline
\end{tabular}

After having utilized the data provided en Table 4 in equations (6) and (7), a value of $0.29 \mathrm{mg} \mathrm{L}^{-1}$ was determined as the detection limit (LOD) and as a quantification limit (LOQ), a value of $0.41 \mathrm{mg} \mathrm{L}^{-1}$. From these values, it can be deduced that the method is indeed useful in terms of quantifying low concentrations of dye.

3.3 Kinetic study of photocatalytic discoloration

3.3.1. Experiment to $\mathrm{pH} 3$ and $0.05 \mathrm{~g}$ of $\mathrm{ZnO}$ per $250 \mathrm{~mL}$ of solution

Taking as a point of reference the experimentation values proposed in Table 2, the solution to $50 \mathrm{mg} \mathrm{L}^{-1}$ was prepared. After having conducted the discoloration trial run, the data presented in Table 5 were obtained. 
Table 5. Results obtained for the Red TS3B discoloration process to a $\mathrm{pH}$ of 3 and a dosage of $0.05 \mathrm{~g}$ of $\mathrm{ZnO}$ per $250 \mathrm{~mL}$ of solution.

\begin{tabular}{|c|c|c|}
\hline Time $(\min )$ & Absorbance & Concentration $\left(\mathrm{mg} \mathrm{L}^{-1}\right)$ \\
\hline 0 & 0.9918 & 53.65 \\
\hline 30 & 0.8945 & 48.45 \\
\hline 60 & 0.8540 & 46.28 \\
\hline 90 & 0.7903 & 42.88 \\
\hline 120 & 0.7290 & 39.60 \\
\hline 150 & 0.6536 & 35.57 \\
\hline 180 & 0.5832 & 31.80 \\
\hline
\end{tabular}

3.3.2. Experiment to $\mathrm{pH} 11$ and $0.05 \mathrm{~g}$ of $\mathrm{ZnO}$ per $250 \mathrm{~mL}$ of solution

Table 6, presents the data obtained from the photocatalytic discoloration process for the established conditions.

Table 6. Results for the discoloration process to a $\mathrm{pH}$ of 11 and a dosage of $0.05 \mathrm{~g}$ of $\mathrm{ZnO}$ per $250 \mathrm{~mL}$ of solution.

\begin{tabular}{|c|c|c|}
\hline Time (min) & Absorbance & Concentration $\left(\mathrm{mg} \mathrm{L}^{-1}\right)$ \\
\hline 0 & 0.9199 & 49.81 \\
\hline 30 & 0.8266 & 44.82 \\
\hline 60 & 0.5089 & 27.83 \\
\hline 90 & 0.3462 & 19.13 \\
\hline 120 & 0.1697 & 9.69 \\
\hline 150 & 0.1215 & 7.11 \\
\hline 180 & 0.0660 & 4.14 \\
\hline
\end{tabular}

3.3.3 Experiment to $\mathrm{pH} 3$ and $0.2 \mathrm{~g}$ of $\mathrm{ZnO}$ per $250 \mathrm{~mL}$ of solution

In Table 7, the data obtained from the photocatalytic process for established parameters in the factorial design are presented.

Table 7. Results from the discoloration process to a $\mathrm{pH}$ of 3 and a dosage of $0.2 \mathrm{~g}$ of $\mathrm{ZnO}$ per $250 \mathrm{~mL}$ of solution.

\begin{tabular}{|c|c|c|}
\hline Time $(\mathrm{min})$ & Absorbance & Concentration $\left(\mathrm{mg} \mathrm{L}^{-1}\right)$ \\
\hline 0 & 0.9411 & 50.94 \\
\hline 30 & 0.5489 & 29.97 \\
\hline 60 & 0.2937 & 16.32 \\
\hline 90 & 0.1331 & 7.73 \\
\hline 120 & 0.0545 & 3.53 \\
\hline 150 & 0.0497 & 3.27 \\
\hline 180 & 0.0483 & 3.20 \\
\hline
\end{tabular}

3.3.4 Experiment to $\mathrm{pH} 11$ and $0.2 \mathrm{~g}$ of $\mathrm{ZnO}$ per $250 \mathrm{~mL}$ of solution

Finally, in Table 8 the results obtained by way of the photocatalytic discoloration of the dye Red TS3B according to the defined parameters in the experimental design are presented.

Table 8. Results from the discoloration process to a $\mathrm{pH}$ of 11 and a dosage of $0.2 \mathrm{~g}$ of $\mathrm{ZnO}$ per $250 \mathrm{~mL}$ of solution.

\begin{tabular}{|c|c|c|}
\hline Time (min) & Absorbance & Concentration $\left(\mathrm{mg} \mathrm{L}^{-1}\right)$ \\
\hline 0 & 0.7995 & 43.37 \\
\hline 30 & 0.3989 & 21.95 \\
\hline 60 & 0.1958 & 11.09 \\
\hline 90 & 0.0802 & 4.90 \\
\hline 120 & 0.0206 & 1.72 \\
\hline 150 & 0.0159 & 1.47 \\
\hline 180 & 0.0088 & 1.09 \\
\hline
\end{tabular}

Fig. 3, presents a comparison of the different results obtained, according to the established parameters in the factorial design.

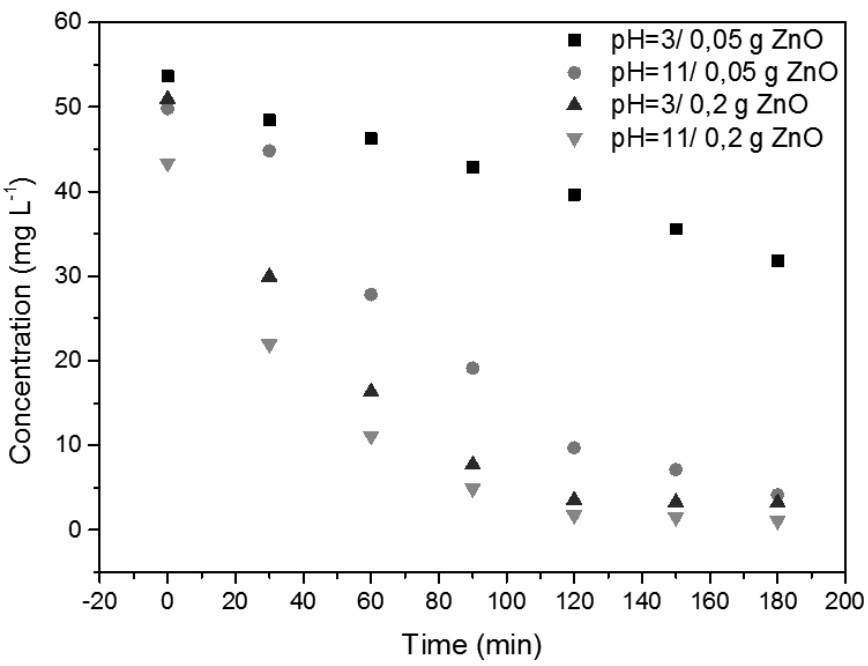

Figure 3. Photocatalytic degradation of the dye Red TS3B to the fixed parameters in the experimental design.

3.4 Evaluation of factorial design

The results obtained in the previous section are summarized in Table 9, after the equation (8) having been applied in each experiment.

Table 9. Degradation percentages obtained with the factorial design experimentation.

\begin{tabular}{|c|c|c|c|}
\hline Experiment & $\mathrm{pH}$ & $\mathrm{ZnO}(\mathrm{g} / 250 \mathrm{~mL})$ & Degradation (\%) \\
\hline 1 & 3 & 0.05 & 40.73 \\
\hline 2 & 11 & 0.20 & 91.68 \\
\hline 3 & 3 & 0.05 & 93.72 \\
\hline 4 & 11 & 0.20 & 97.50 \\
\hline
\end{tabular}

Upon observing the results, it becomes obvious that the best combination of variables is to work to a $\mathrm{pH}$ of 11 and a dosage of $0.2 \mathrm{~g}$ of $\mathrm{ZnO}$ per each $250 \mathrm{~mL}$ of dye solution. Nevertheless, conducting a deeper statistical analysis, Figure 4, presents the repercussion of the factors in the degradation because upon increasing them, an even better degradation is achieved.

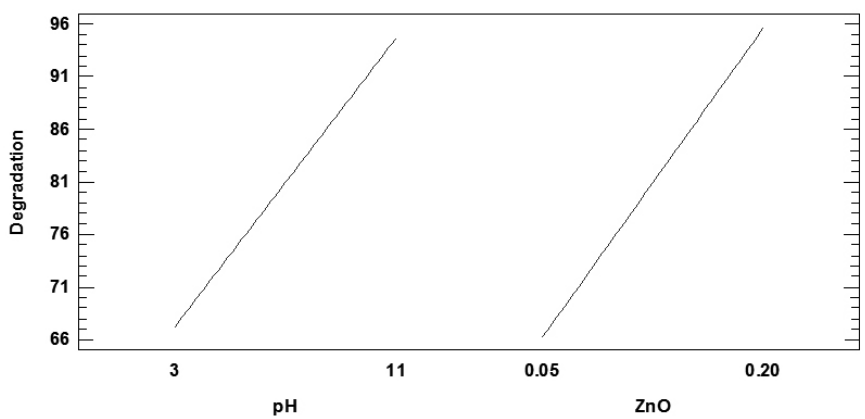

Figure 4. Behavior of the factors for the degradation process.

On the other hand, the representation of the mathematical model obtained by the factorial design is known as the surface-answer graphic. Figure 5 presents the values of $\mathrm{pH}$ and dosage of $\mathrm{ZnO}$ in order to obtain an adequate percentage of degradation. 


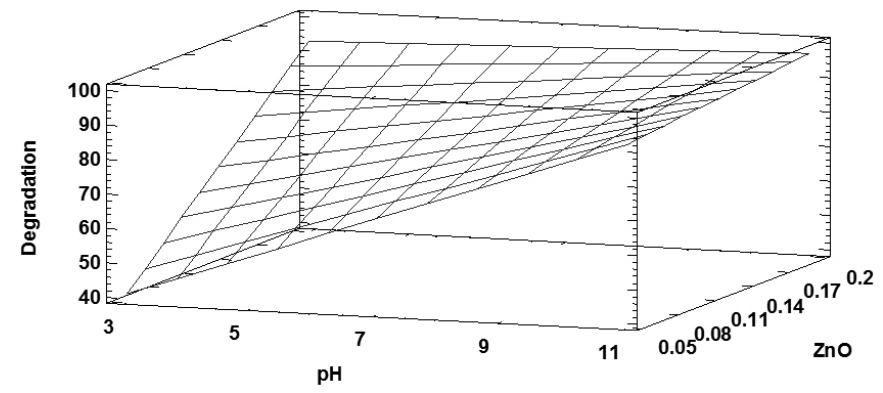

Figure 5. Surface-answer graphic for the discoloration of Red TS3B.

In order to achieve a better visualization, a projection of the solid above the lower plane is effected, achieving what is called the curve of iso-values, which is presented in Fig. $\mathbf{6}$ and from which it is deduced that in order to achieve maximum degradation, one must work to a $\mathrm{pH}$ of 11 and an dosage increased to $0.2 \mathrm{~g}$ of $\mathrm{ZnO}$ per $250 \mathrm{~mL}$ of solution.

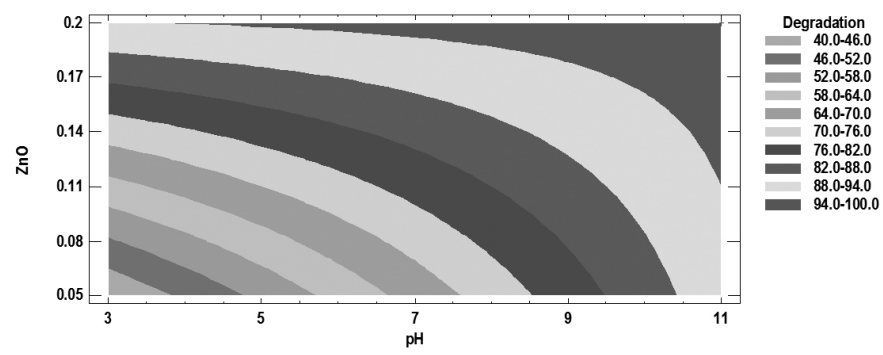

Figure 6. Graphic of iso-values for the degradation of the dye Red TS3B.

Table 10 presents the levels of the experimental factors which guarantee a maximum percentage of degradation, being able to achieve up to $97.5 \%$ degradation.

Table 10. Data for obtaining maximum degradation.

\begin{tabular}{|c|c|c|c|}
\hline Factor & Low & High & Optimum \\
\hline $\mathrm{pH}$ & 3 & 11 & 11 \\
\hline $\mathrm{ZnO}(\mathrm{g} / 250 \mathrm{~mL})$ & 0.05 & 0.20 & 0.20 \\
\hline
\end{tabular}

For this photocatalytic degradation process, a mathematical model is proposed, which could include the three components remaining defined in the equation (10).

Degradation $(\%)=-1.94+8.33 p H+471.19 \mathrm{ZnO}-39.31 p H \cdot \mathrm{ZnO} 10)$

The model presents a $\left(r^{2}\right)$ close to 100.00 which means that the results for the most part depend on the $\mathrm{pH}$ and the dosage of $\mathrm{ZnO}$. Similarly, Fig 7 presents the discoloration obtained a product of the optimization of the photocatalytic process.

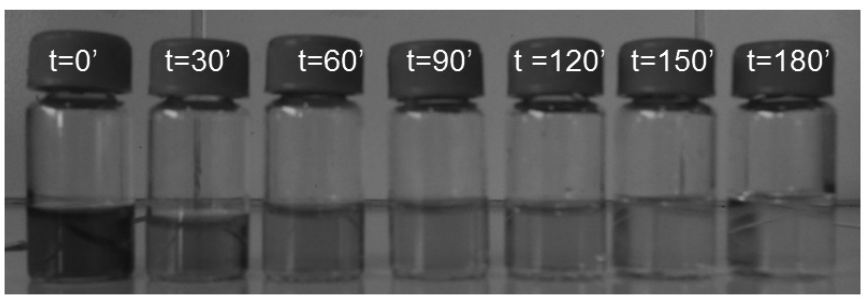

Figure 7. Discoloration of the dye Red TS3B to a $\mathrm{pH}$ of 11 and a dosage of 0.2 of $\mathrm{ZnO}$ per $250 \mathrm{~mL}$ of solution.

\section{DISCUSSION}

A degradation of $97.5 \%$ was obtained when a $\mathrm{pH}$ of 11 and a dosage of 0.2 $\mathrm{g}$ of $\mathrm{ZnO}$ per $250 \mathrm{~mL}$ of solution of the dye Red TS3B were utilized. Rahman et al. [6] has reported an approximately $95 \%$ discoloration when a Rhodamine B solution was worked with. While conceding that this is true, this degradation was achieved in a period of 70 minutes of exposure to ultraviolet radiation. It must also be taken into account that $\mathrm{ZnO}$ nanostructures were worked with, a technique which upon increasing the contact surface of the photocatalyst, possibly optimizes the degradation time because in our case only sifted $\mathrm{ZnO}$ was worked with.

Sakthivel et al. [7] experimented with direct radiation, comparing the efficiency of the $\mathrm{TiO}_{2}$ versus the $\mathrm{ZnO}$, utilizing acid Brown 14 as a dye, which is characterized by possessing an azo group similar to the dye utilized in the present research project. In a manner analogous to our own research, up to $92.81 \%$ dye degradation was achieved in 180 minutes of reaction. This leaves us with the interesting fact that the ultraviolet radiation inherent in direct solar radiation is not nearly as energetic as the case which Corzo et al. [8] reported, in which degradation results in less reaction time were achieved.

Due to the elevated degradation percentage of azoic dyes, which are widely utilized in the textile industry and which generate a serious problem the moment the water is treated, photocatalysis with $\mathrm{ZnO}$ becomes an extremely attractive alternative in order to effect the mineralization of these compounds, such as that which Byrne et al. [3] indicates and proposes upon having catalogued the generation of radicals as the principal source of what are called Advanced Oxidation Processes.

\section{CONCLUSIONS}

Utilizing a sieve $\mathrm{N}^{\circ} 200$, a granulometric adaptation of $\mathrm{ZnO}$ was realized The analytic methodology for the quantification of the dye Red TS3B presented an answer directly proportional to the concentration, being linear and sensitive for its determination. The optimal parameters for the discoloration process suggest a $\mathrm{pH}$ of 11 and $0.2 \mathrm{~g}$ of $\mathrm{ZnO}$ per $250 \mathrm{~mL}$ of colored solution. A degradation of $97.5 \%$ was achieved when the optimal parameters of the factorial design were worked with.

\section{ACKNOWLEDGEMENTS}

The authors would like to express their gratitude to Engineer Fredy Molina from the company Franky \& Ricky for having provided the dye necessary in order to have realized the present research project and, likewise, to Dr. Jose A. Villanueva Salas for permitting us to develop and execute the experimental part of our research in Laboratorio del Proyecto Mercurio (H-202), Universidad Católica de Santa María, Arequipa.

\section{REFERENCES}

1. Soares, P.A., Silva, T.F.C.V., Manenti, D.R et al. Environ. Sci. Pollut. Res. 21, 932 (2014)

2. Mittal, M., Sharma M., Pandey O.P. Sol. Energy. 110, 386 (2014).

3. Byrne, C., Subramanian G., Pillai S.C. Recent Advances in Photocatalysis for Environmental Applications. J. Environ. Chem. Eng. (2017).

4. Achouri F., Corbel S., Aboulaich A., Balan L., Ghrabi A., Said M.B., Schneider R. J. Phys. Chem. Solids. 75, 1081, (2014).

5. Daneshvar, N., Salari D., Khataee A.R. J. Photochem. Photobiol. A Chem. 162, 317 (2004).

6. Rahman, Q.I., Ahmad M., Misra S.K., Lohani M. Mater. Lett. 91, 170 (2013).

7. Sakthivel, S., Neppolian B., Shankar M.V., Arabindoo B., Palanichamy M., Murusugesan V. Sol. Energy Mater. Sol. Cells. 77, 65 (2003).

8. Corzo, A., Vega J. Rev. Iberoam. Pol. 13, 60 (2012). 